\title{
ANFETAMINAS E DROGAS DERIVADAS
}

\author{
AMPHETAMINES AND DERIVATE DRUGS
}

Irene Batista Muakad*

\begin{abstract}
Resumo:
Sintetizada pela primeira vez na Alemanha, a anfetamina é, portanto, droga sintética, fabricada em laboratório, a qual, por sua vez, estimula o sistema nervoso central. A anfetamina faz com que o cérebro funcione mais rápido do que o normal, acarretando um estado hiperativo nos indivíduos usuários.
\end{abstract}

Palavras-chave: Anfetaminas. Composto de anfetaminas. Metanfetamina. Dextroanfetamina. Anfetaminas puras. "Psicose anfetamínica".

\begin{abstract}
:
Synthesized for the first time in Germany, amphetamine is a synthetic, laboratory produced drug, which stimulates the central nervous system. Amphetamine makes brain activities to run faster than normal, causing a hyperactive state in individuals.

Keywords: Amphetamines. Compound of amphetamine. Methamphetamine. Dextroamphetamine. Pure amphetamine. "Amphetamine psychosis."
\end{abstract}

\section{Histórico}

A natureza humana é caracterizada pela busca da felicidade, pela fuga de ambientes pouco hospitaleiros e pela tentativa de evitar situações desagradáveis ou dolorosas, enfim, busca principalmente o prazer.

Todavia, nunca se comentou tanto sobre "stress", subnutrição, condições precárias de vida, ambientes competitivos, tensão social, desemprego, insegurança, violência, consumismo, frustração, miséria, riqueza, solidão no meio da multidão etc...

Tudo isso contribui para que algumas pessoas sejam influenciadas pela fantasia de uma busca fácil e rápida de soluções para seus problemas. Assim, penetram no estranho mundo das drogas. Muitos são os fatores que podem contribuir para que um indivíduo fique sujeito ao uso de drogas: adquirir coragem ou se sentir mais forte frente às dificuldades; desejo de ser aceito em um grupo; curiosidade; busca de sensação de segurança ou de euforia; fugas; sentir-se mais calmo e estimulado; fácil acesso às drogas; saúde deficiente; falta de informações corretas sobre os efeitos

Professora Doutora de Medicina Forense do Departamento de Direito Penal, Medicina Forense e Criminologia da Faculdade de Direito da Universidade de São Paulo. Professora Titular de Medicina Forense da Faculdade de Direito da Universidade Presbiteriana Mackenzie. 
das drogas; descontentamento com a postura familiar, principalmente com os pais ou da sociedade em que vive.

Segundo a Organização Mundial da Saúde "Droga é toda substância natural ou sintética que, introduzida no organismo vivo, pode modificar uma ou mais de suas funções”. Nos termos do art. $1^{\circ}$, parágrafo único da Lei n. 11.343 de 26-08-2006, “drogas são substâncias ou produtos capazes de causar dependência, assim especificados em lei ou relacionados em listas atualizadas periodicamente pelo Poder Executivo da União", e, pelo exposto, notamos que o termo drogas substituiu a expressão "substâncias entorpecentes".

Em outras oportunidades já nos manifestamos sobre a maconha, merla, cocaína e o crack, desta vez abordaremos uma parte das drogas utilizadas nas raves (festa onde os frequentadores dançam noite adentro, ao som de música eletrônica: mega-rave: são raves de grandes proporções, com milhares de pessoas). ${ }^{1}$ As “club drugs" são, na maior parte, utilizadas por jovens adultos, com boa formação escolar, inseridos no mercado de trabalho e pertencentes a classes sociais privilegiadas; são o álcool, LSD, Special K e o PCP, Poppers, Rphypnol as anfetaminas e as suas diversas variações. Abordaremos as anfetaminas e as suas variações.

A anfetamina é uma droga sintética, fabricada em laboratório, que estimula o sistema nervoso central, fazendo com que o cérebro trabalhe muito e mais rápido do que o normal, deixando as pessoas mais "ligadas", elétricas, sem sono, isto é, a pessoa fica num estado hiperativo. Sendo seus efeitos muito semelhantes aos da cocaína.

A anfetamina foi sintetizada pela primeira vez na Alemanha, pelo químico Lazar Edeleanu em $1887 .{ }^{2}$ Cerca de 40 anos depois a droga começou a ser utilizada medicinalmente para aliviar a fadiga, alargar as passagens nasais e bronquiais (em casos de asma) e estimular o sistema nervoso central. Sua primeira versão comercial, com o nome Benzedrine, e em forma de pó para inalação descongestionante nasal, surgiu na França em 1932. Cinco anos mais tarde a Benzedrine surgiu na forma de pílulas, chegando a vender mais de 50 milhões de unidades nos três primeiros anos após a sua introdução no mercado. Entre 1932 e 1946 a indústria farmacêutica desenvolveu uma lista de 39 usos clínicos para a anfetamina. ${ }^{3}$

Durante a II Guerra Mundial foi usada para aumentar o estado de alerta e reduzir a sensação de fadiga das tropas dos aliados e das potências do Eixo.

Nos Estados Unidos, o uso da anfetamina pelos militares só foi oficialmente autorizado a partir da Guerra da Coréia. Perto do final da guerra, os operários das fábricas

1 CARLINI, Elisaldo de Araújo et al. O uso do êxtase (MDMA) na cidade de São Paulo e imediações: um estudo etnográfico. Jornal Brasileiro de Psiquiatria, v. 51, n. 2, 2002.

2 CEBRID. Anfetaminas. Disponível em: < http://www.unifesp.br/dpsicobio/cebrid/folhetos/anfetaminashtm> Acesso em: jun. 2012.

3 Id. Ibid. 
japonesas de munição, recebiam generosos suprimentos de drogas, anunciadas como solução para a sonolência e desânimo, pois, além de inibidoras do apetite, elas também podiam provocar um estado de grande excitação e sensação de poder. Mas a distribuição indiscriminada, durante e pós-guerra, acabou gerando 500 mil novos viciados no Japão. ${ }^{4 / 5}$

No início da década de 50, militares americanos servindo no Japão e na Coréia foram os primeiros a utilizar uma mistura injetável de anfetamina e heroína denominada "speedball". A verdade é que após o término da guerra de 45, o mundo foi invadido pela anfetamina, especialmente por dois derivados a melanfetamina (Pervitin) e a fenmetrazina (Perludin). Com o uso dessas drogas, pretendia-se a redução da fadiga, do sono e do apetite além do aumento da capacidade de trabalho. Os viciados em heroína eram tratados com injeções intravenosas de anfetamina. Todavia, sendo constatado que o consumo abusivo levava, além dos efeitos sabidos, a um comportamento violento, seu uso começou a ser proibido.

\section{- Espécies}

Em estado puro, as anfetaminas têm forma de cristais amarelos, com sabor muito amargo. Geralmente são ingeridas por via oral em cápsulas ou comprimidos de cinco miligramas, podem também ser consumidas via intravenosa, diluída em água destilada, ou ainda aspirada em forma de pó, ou dissolvida em bebida alcoólica.

Sob a designação geral de anfetaminas, existem diferentes categorias de drogas sintéticas que são semelhantes sob o ponto de vista químico: "as Anfetaminas, propriamente ditas, dextroanfetamina e a metanfetamina". ${ }^{6}$ Existem no mercado vários produtos que podem ser enquadrados numa dessas três categorias como: Benzedrine e Bifetamina, anfetaminas puras; dexedrine, um sulfato de dextroanfetamina, com estrutura molecular semelhante ao hormônio epinefrine (adrenalina) que é uma substância secretada no corpo humano pela glândula supra-renal nos momentos de susto; dexamyl, uma combinação de dextroanfetamina e amobarbital, um sedativo; methedrine e desoxyn, metanfinas puras; desbutal e obedrin, combinações de metanfetamina e pentobarbital, um barbitúrico; e amphaplex, um coquetel de metanfetamina, anfetamina e dextroanfetamina. Preludin, uma droga que difere quimicamente das anfetaminas, e é enquadrada nesse grupo por causar os mesmos efeitos.

\footnotetext{
$4 \quad$ CEBRID. Anfetaminas. cit.

5 ALMEIDA, Stella Pereira de. Sintéticas, recreativas e ilegais: Drogas de uma "Geração Química". In: SILVEIRA, Dartiu Xavier da. Panorama atual de drogas e dependência. São Paulo, Atheneu, 2006. p. 179 6 DEL-CAMPO, Eduardo Roberto Alcântara. Medicina legal II. São Paulo: Saraiva, 2009. p. 116. (Coleção curso \& Concurso; coordenação Edilson Mougenot Bonfim).
} 


\section{- Usuários}

Durante muito tempo a anfetamina foi utilizada para tratar depressão, epilepsia, mal de parkinson e narcolepsia (estado constante de sono), todavia, até bem pouco tempo apenas a narcolepsia e os regimes controlados, permaneciam utilizando essa droga em seu tratamento médico lícito.

Os derivados de anfetamina faziam parte, dos inibidores de apetite, usados em regimes de emagrecimento, tanto dos medicamentos fabricados em laboratórios farmacêuticos, como das "fórmulas de emagrecimento" preparadas em farmácias de manipulação. ${ }^{7}$ De acordo com a Revista Veja "apesar dos efeitos colaterais provocados pelo uso frequente e do risco de dependência psíquica/e ou química, e outros meios de comunicação, o Brasil é o país que mais utiliza essa substância para efeitos de perda de peso", e de acordo com a Anvisa, isto se deve, principalmente, ao seu clima tropical que desencadeia o exagerado culto ao corpo. ${ }^{8}$ "Na era da celebridade e das mediocridades, do glamour e da fraude, do espetáculo e da especulação, a aparência é tudo (...) ta baixo astral toma prozac; ta sem tesão toma viagra; ta sem dinheiro, então se mata; de preferência em público, que o show não pode parar. Um refrão adequado a esta era em que vivemos seria: Se você não é quem queria ser, ao menos aparente ser o que não é (...). Os três imperativos éticos da atualidade são egocentrismo, hedonismo e consumismo (Nicolau Sevcenko), Carta Capital). Benzodiazepínicos e Anfetaminas na Era do Ego. ${ }^{9}$

Aqui, a anfetamina é conhecida como "emagrecedores", que receitados e tomados como parte integrante de regimes de emagrecimento, frequentemente escapavam do controle do médico e do próprio paciente, que passava a viver uma dependência química. Comumente o paciente acabava consultando vários médicos em busca de receitas médicas "com que fazia tratamento", com a desculpa de que tinha que tomar "senão engordo de novo", ou pior, buscava no mercado ilegal para suprir sua dependência. Como as anfetaminas, além de suprimir o apetite, também prejudicam o sono e causam irritabilidade e ansiedade, na tentativa de contrabalançar estes efeitos colaterais, um calmante benzodiazepínico (que também gera dependência) era acrescentado à anfetamina na maioria dos medicamentos e fórmulas manipuladas. Nas últimas décadas ocorreu o uso em grande escala das anfetaminas em tratamento para emagrecer no Brasil e no mundo, tendo em vista que é um produto barato e de fácil fabricação, o que mantém um comércio clandestino bastante rico. A verdade é que a própria medicina estava entusiasmada com

\footnotetext{
Revista Veja, São Paulo, 11 de jun. de 1997; O Estado De São Paulo, São Paulo, 01-03-2007. p. C9. Disponível em: <http://www.anvisa.com.br>. Acesso em: jun. 2012.

9 SILVEIRA, Dartiu Xavier da; MOREIRA, Fernanda Gonçalves. Panorama atual das drogas e dependências. São Paulo: Atheneu, 2006.
} 
as anfetaminas, pelo seu amplo emprego. Mas como a perda do apetite, gerada pelo seu uso constante, acabou levando a graves casos de anorexia, com perda de peso, desnutrição e até a morte, o uso desse produto chamou a atenção das autoridades competentes, que se colocaram a campo para retirar do rol dos componentes dos medicamentos para tratamentos de obesos, o uso das anfetaminas o que acabou ocorrendo em 2011, mesmo porque no Brasil, além das anfetaminas, eram colocados nas "fórmulas" tranqüilizantes, hormônio da tireóide, diurético, laxativo, antidepressivo e outro moderador de apetite para a aceleração do emagrecimento.

O exame de densitometria óssea de mulheres que tomaram hormônio para tireóide durante anos, para emagrecer revelou perda óssea muito maior do que o aceitável para a idade. Além disso, a associação desse hormônio com anorexígenos aumenta a probabilidade da ocorrência de taquicardia e arritmia cardíacas.

\section{- Efeitos gerais}

Efeitos Agudos - As anfetaminas agem estimulando o sistema nervoso central através de uma intensificação da norepinefrina, um neuro-hormônio que ativa partes do sistema nervoso simpático. Efeitos semelhantes aos produzidos pela adrenalina no cérebro, são causados pelas anfetaminas, levando o coração e os sistemas orgânicos a funcionarem em alta velocidade, com isto os batimentos cardíacos são acelerados ocorrendo uma hipertensão.

Ao agir sobre os centros de controle do hipotálamo, ao mesmo tempo em que reduz a atividade gastrintestinal, a droga inibe o apetite e seu efeito pode durar de quatro a quatorze horas, dependendo da dosagem. A anfetamina é assimilada rapidamente pela corrente sanguínea e, logo depois de ser ingerida, provoca arrepios seguidos de sentimentos de confiança e presunção. As pupilas dilatam, a boca fica seca, a respiração torna-se ofegante, o coração bate freneticamente, há grande excitação e ranger dos dentes, uma sensação de poder e, a fala fica atropelada. Em seguida, o usuário da droga pode entrar em estado de euforia, enquanto seu corpo se agita com uma intensa liberação de energia, tem sensação de bem estar, de alegria, de alívio da fadiga e por isso a anfetamina é muito procurada por adolescentes em busca de sensações novas, ou por adultos, que desejam ajuda para seus desânimos e suas depressões.

O usuário de anfetamina é capaz de executar uma atividade qualquer por mais tempo, sentindo menos cansaço. Este só aparece horas após o fim do efeito da droga e se nova dose é tomada, o cansaço desaparece, todavia com menor intensidade, isto porque há a tolerância farmacológica, e o resultado é que são necessárias doses cada vez maiores para a produção do bem-estar já alcançado. De qualquer maneira a anfetamina faz 
com que um organismo reaja acima de suas capacidades, exercendo esforços excessivos, prejudicando, a médio e longo prazo, a saúde do usuário.

Ao parar de tomar a droga, a pessoa sente uma grande falta de energia (astenia) ficando bastante deprimida não conseguindo realizar tarefas comuns feitas normalmente antes do vício.

A anfetamina produz midríase (dilatação de pupila), aumento do batimento cardíaco e hipertensão. O sono é pouco reparador.

Quando a anfetamina é tomada continuamente, o usuário começa a perceber que com o tempo a droga faz menos efeito; assim, para obter o que deseja, precisa ir tomando, a cada dia, doses maiores. Há casos que de $1-2$ comprimidos, a pessoa passou a tomar até 40 - 60 comprimidos diariamente. Este é o fenômeno da tolerância, ou seja, o organismo acaba por se acostumar ou ficar tolerante à droga. ${ }^{10}$

É muito comum o uso de mais de um comprimido de uma só vez e nesses casos começam aparecer agressividade, irritação, suspeição de que todos estão tramando contra si, é o chamado "delírio persecutório" e, dependendo do excesso da dose e da sensibilidade da pessoa pode aparecer um verdadeiro estado de paranoia e até alucinações; overdoses fatais, no entanto, são raras, e a dosagem letal ainda é desconhecida, sendo que os usuários habituais podem chegar até 1000 miligramas por dia. O grande problema é a associação com álcool e outras drogas.

Quando há intoxicação grave a respiração é superficial e podemos encontrar até colapso circulatório. Com o passar do tempo o usuário pode apresentar dores de cabeça, náuseas, insônia, acessos de contrações musculares e anorexia, atividade motora excessiva. $\mathrm{O}$ que se tem notado mais recentemente é o aumento de açúcar no sangue e diminuição da sensibilidade à dor.

Efeitos Crônicos - Como o efeito da droga é pouco duradouro e termina em depressão, o usuário é levado a tomar doses seguidas, que vão aumentando na quantidade de anfetamina ingerida à medida que o organismo vai se acostumando à droga. $\mathrm{O}$ ciclo de abuso e dependência pode criar uma reação tóxica no organismo, conhecida como psicose anfetamínica, que pode durar até algumas semanas, com irritabilidade, insônia, alucinações e eventualmente a morte.

Ao contrário do que se pensa, a droga causa dependência psicológica, podendo chegar a tal ponto de abandono exigindo permanente apoio clínico e psicológico para superar a síndrome de abstinência.

10 MANCINIEN, Márcio. Anorexígenos. Disponível em: <http://drauziovarella.ig.com.br>. Acesso em: jun. 2012. 
Trabalhos recentes em animais de laboratórios mostram que o uso continuado de anfetamina pode levar à degeneração de determinadas células do cérebro, o que indica a possibilidade de lesões irreversíveis em pessoas que abusam destas drogas.

Efeitos do uso no comportamento - A anfetamina aumenta a atividade física e produz inquietação na maioria dos indivíduos. O usuário torna-se agitado e incapaz de permanecer sentado. Se confinado a um pequeno aposento, aparenta ansiedade por se sentir preso a uma pequena área e insiste em sair. Um estudante que toma anfetamina para estudar até tarde da noite, ainda se sentirá desperto após a conclusão do trabalho, passando a procurar o que fazer.

Anfetaminas também levam o usuário a falar sem parar sobre os assuntos mais variados; fala com tanta rapidez que fica muito difícil compreender o que ele diz. Muda de assunto seguidamente até que a conversa perca o sentido.

Há relatos de julgados isolados dando a guarda de filhos a mães viciadas em anfetaminas, considerando sem perigo algum tal dependência química. Essas mães normalmente começaram a tomar a droga principalmente em virtude do culto ao corpo, e, sendo assim, não se alimentam e nem fazem as refeições adequadas aos filhos sob sua guarda. Acompanhando um desses casos julgados, por alguns anos, pudemos constatar o resultado de uma decisão açodada e pouco raciocinada. Com os efeitos da anfetamina, principalmente, quanto à fala atropelada, e falta de sono, o bem estar da criança, no dia a dia, fica prejudicado, acabando por demonstrar nas atitudes da mesma a influência negativa da convivência com uma mãe dependente química. O pior, gerando na criança aversão pela mãe, que na realidade é doente, necessitando de sério tratamento. O que deveria ser decidido, se é que a regra é pensar e cuidar do bem estar do menor, era determinar a alteração da guarda do mesmo, ainda que provisoriamente e o encaminhamento da mãe para tratamento, pois esse tipo de dependência química não é tão despida de prejuízo, para a criança, quanto se pensa.

Os efeitos mais comuns do estímulo cerebral por anfetamina são: a euforia, rapidez nas reações, aumento da auto-estima e da autoconfiança. A pessoa sente-se menos cansada e com o raciocínio mais claro, mas, embora pense que seu desempenho melhorou, na realidade, sua atividade mental reduziu. A verdade é que a anfetamina reduz a eficiência em qualquer trabalho que envolva raciocínio e criatividade. A autoconfiança se baseia no estímulo cerebral produzido pela anfetamina, não significando que a eficiência no trabalho tenha sido alcançada.

Efeitos da Anfetamina no Ato de Dirigir- A anfetamina entre os caminhoneiros é denominada "rebite", "bolinhas", que causam profundo efeito no desempenho ao volante, naqueles que trabalham no período noturno sendo facilmente 
adquiridas. Esses profissionais precisam dirigir muitas horas seguidas, sem pausas para descanso, para cumprir os prazos exíguos dos fretes e as longas jornadas de trabalho a que são submetidos. Trata-se de uma substância química sintetizada pela indústria farmacêutica, que atua no organismo humano estimulando a atividade do SNC. O rebite faz com que o cérebro trabalhe mais depressa, aumenta a capacidade física e diminui a sensação de fadiga. Deixa os usuários "acesos", "ligados", "com menos sono", presos ao volante, efeitos estes buscados pelos caminhoneiros. ${ }^{11}$ A droga aumenta as probabilidades de acidentes, uma vez que produzem euforia e disposição para enfrentar riscos em uma pessoa que já está cansada. Seus efeitos negativos dependem da quantidade da droga ingerida, e também do uso simultâneo de outras drogas. O álcool reduz a capacidade de dirigir, porque sendo um depressor da atividade cerebral, ainda que em baixas quantidades, provoca entorpecimento e diminuição dos reflexos; mas quando tomado por uma pessoa que tenha ingerido o "rebite", esses efeitos desaparecem devido à sua capacidade de estimular o cérebro. Como já foi dito, anteriormente, a anfetamina gera uma autoconfiança, sendo assim, os motoristas se arriscam nas estradas, e colocam em risco também, a vida dos demais motoristas.

O mais triste no que se refere ao uso de drogas para dirigir muitas horas seguidas, e esses acidentes, é que, as últimas investidas da polícia, no sentido de atacar os traficantes de beira de estrada, levou a uma alarmante realidade, um número muito grande de motoristas que começaram com a anfetamina já estão usando com frequência a cocaína. Estaria aí a explicação para o aumento do número considerável de acidentes graves e/ou com óbitos nas estradas envolvendo caminhões.

Doping - É qualquer substância que ministrada ao organismo aumenta, artificialmente, o seu rendimento em competições. Esta é a definição mais simples e resumida do doping esportivo.

O primeiro caso de doping detectado em laboratório foi do ciclista Kurt Jansen que morreu durante uma prova de estrada nos jogos olímpicos de Roma em 1960. O ciclista inglês Tom Simpson em 13 de julho de 1967, vítima de infarto agudo do miocárdio durante a prova "Mont Ventoux", na França. Nos dois casos a autópsia acusou a presença de estimulantes do tipo anfetamina, e a partir daí iniciou-se a organização para o Controle Anti-Doping nas competições internacionais e olímpicas, sendo que o primeiro Controle Anti-Doping ocorreu nos jogos olímpicos de 1968 na Cidade do México.

Apesar disso, a incidência de casos de usuários da droga especialmente entre jogadores de futebol e baseball, ainda é grande. Corredores e nadadores fazem uso de anfetamina, para aumentar a energia e resistência. $\mathrm{O}$ aumento no desempenho é explicado

11 Disponível em: $<$ http://www.fenatac.org.br/niveis/noticias/noticias_irresponsabilidade_coletiva.html $>$. 
pela propriedade desse tipo de droga de mascarar os sintomas de fadiga, levando o atleta a ultrapassar seus limites de segurança e resistência; jóqueis recorrem àquela para suprimir o apetite e evitar o aumento do peso corporal.

Efeitos da Anfetamina no Cérebro e no Corpo - Células especiais chamadas neurônios compõem o cérebro. Esses neurônios são agrupados em padrões e localizações específicos, funcionando como estações retransmissoras que regulam as inúmeras atividades do organismo.

Um complexo arranjo de axônios interliga as diferentes áreas do cérebro. Através de impulso elétrico mensagens são transmitidas entre os axônios; o estímulo é transferido quimicamente para o próximo neurônio e, é esse sistema alternativo eletroquímico que transporta mensagens de uma parte do cérebro para outra.

Os compostos químicos usados nesse processo são denominados "neurotransmissores", porque são responsáveis pelas comunicações entre os neurônios. Cerca de trinta diferentes tipos de neurotransmissores já foram encontrados no cérebro, sendo que, os mais importantes para a produção dos efeitos das anfetaminas são a noradrenalina e a dopamina.

Quando as anfetaminas entram em contato com um terminal axônico, é liberado um excedente desses neurotransmissores, provocando uma resposta mais forte. Como a anfetamina é desativada muito lentamente pelo organismo, será necessário mais tempo para que o excesso de noradrenalina e dopamina seja consumido, o que resulta num efeito mais prolongado. Esses dois neurotransmissores encontrados nos neurônios e no tecido orgânico acabam tendo suas funções modificadas pela anfetamina e, como consequência todo perfeito funcionamento do corpo humano também é afetado.

Efeitos da Anfetamina no Coracão e nos Vasos Sanguíneos - Os efeitos das anfetaminas sobre o coração e nos vasos sanguíneos dependem da dose tomada. Após pequenas doses, de 5 a 10mg, a pressão sanguínea se eleva. Essa elevação é registrada pelo cérebro, que envia sinais ao coração para que bata mais devagar. Doses maiores de $25 \mathrm{mg}$ agem diretamente sobre o coração, aumentando o ritmo e a força das contrações; essa é a taquicardia ou aceleração dos batimentos cardíacos. Disritmias podem decorrer da utilização de mais que $100 \mathrm{mg}$.

Doses extremamente altas de anfetaminas podem causar danos permanentes nos vasos sanguíneos, que irrigam o córtex cerebral, bem como o rompimento desses vasos, trazendo consequência fatal ou um derrame com risco de paralisia permanente.

Efeitos da Anfetamina na Gravidez - As mulheres em geral percebem a gravidez quando há um atraso da menstruação, mesmo assim, até a comprovação, geralmente continuam a tomar a anfetamina, ou porque querem continuar o regime de emagrecimento ou pelo vício. 
Nos primeiros estágios da gravidez, o embrião cresce e se desenvolve muito rapidamente e qualquer distúrbio durante essa fase pode levar a intoxicação do mesmo, a má formação e ainda a um grande número de anormalidades no bebê. $\mathrm{O}$ feto por ser muito pequeno é altamente vulnerável às drogas, e as doses tomadas pela mãe, para ele são muito grandes, na medida em que seu fígado ainda não se desenvolveu o suficiente. Os efeitos maléficos das anfetaminas no feto são irreversíveis. Um efeito colateral muito comum notado nos recém nascidos, filhos de mães usuárias de anfetaminas, é o choro insistente bem como o diagnóstico de fissura ano-retal, produzida pela grande acidez das fezes, em razão da presença residual da anfetamina passada pela mãe via placentária. A suspensão do uso não diminui em nada os danos já causados na criança. A vulnerabilidade dos filhos de usuárias ou ex-usuárias, frente às drogas, é muito grande, exigindo cuidados e atenção especiais. A ideia da mãe, de que seja suficiente haver parado no momento que descobriu a gravidez, é totalmente enganosa!!!

- Quando o uso se torna abuso

Entende-se por abuso de drogas o uso indevido ou uso por motivos nãomedicinais.

As drogas estão cada vez mais acessíveis e usadas socialmente. Por isso fica muito difícil ao jovem, decidir se deve ou não experimentá-la, e questionar o uso de uma droga, que o faz sentir-se tão bem.

A questão envolve a forma de como a pessoa consegue lidar com seus problemas; depressão, baixo nível de auto-estima ou necessidade de integrar-se a um grupo de amigos.

O usuário, dificilmente pensa que é dependente. Normalmente pensa que pode parar quando quiser. "Não sou viciado" e "Por que devo parar, se as drogas me fazem sentir tão bem?" "O usuário compara as drogas alegando que a outra vicia”, "mas, a sua "droga", ele pode abandonar facilmente".

A família sempre hesita em interferir, mesmo tendo alguma suspeita. Quando o abuso chega a causar impacto na família, o problema da anfetamina já está muito sério. É hora de procurar aconselhamento familiar, ajuda profissional, ou a Polícia se houver violência.

- Estágios do uso indevido de anfetamina

Uso Ocasional - Consiste no consumo de uma ou duas vezes por semana, em baixas doses, de 5 a $20 \mathrm{mg}$., o que corresponde a quatro "bolinhas". 
Nesse estágio, o indivíduo usa a anfetamina com o objetivo de evitar fadiga, recuperar-se de uma ressaca, elevar o ânimo durante o cumprimento de tarefas importantes ou simplesmente para ficar alegre.

Uso Constante em baixas doses - Os usuários obtêm normalmente suas "bolinhas" com receita médica para controle de peso, mas passam a tomar doses maiores, três a quatro vezes a recomendada, procurando, assim sustentar um estado de euforia. Às vezes uma pessoa consulta mais de um médico, para obter mais receitas, necessárias para a aquisição de anfetaminas suficientes para o seu uso diário.

A anfetamina produz efeitos lentamente, diferente da cocaína que age rapidamente. Aquele que usa anfetamina não experimenta mudanças rápidas da euforia para a depressão e de novo para a euforia, como no caso da cocaína. Para manter o efeito da cocaína seria necessário tomar uma dose a cada meia hora. Já os efeitos da anfetamina duram por várias horas.

Com o uso diário de anfetamina, o indivíduo começa a acreditar que não sobrevive sem ela e quando há dificuldades para dormir ele compensa com o uso de depressores como o álcool ou barbitúricos, sendo esse tipo de comportamento muito comum e bastante perigoso.

Uso indevido em altas doses - Corresponde ao consumo de doses de 400 a $1000 \mathrm{mg}$. por via intravenosa, o que é ainda mais perigoso. Esse estágio caracterizase por uma "aceleração" logo após a injeção, seguida por exaustão e reação depressiva. As injeções podem ser repetidas a cada duas ou três horas, por vários dias seguidos, tornando o comportamento do usuário violento. Depois, cai no cansaço, para de se injetar entrando em exaustão. Nessa fase não é raro o usuário dormir por dois ou três dias. A sintomatologia seguinte é a depressão a letargia a debilitação física, que podem durar dias ou várias semanas, sendo possível, nessa fase o usuário injetar-se novamente para sair desse estado de depressão.

A anfetamina e o vício

Toda pessoa que fica viciada, para obter o efeito que experimentou na primeira vez que usou a droga, necessariamente aumenta a dose a ser ingerida. A essa necessidade orgânica dá-se o nome de "tolerância".

No caso da anfetamina o processo é igual. Sua tolerância leva a uma diminuição quanto à sensibilidade à droga e o consumidor tem, muitas vezes, que aumentar suas doses, em cinquenta ou cem vezes mais para atingir o efeito desejado.

Esse fenômeno da tolerância pode ser comprovado pelos seus efeitos adversos; é o que ocorre a uma pessoa que habitualmente não usa droga e vem a óbito, tomando uma quantidade que não faria efeito algum num usuário habitual. 
Não é muito conhecido ainda o processo pelo qual o organismo humano cria a tolerância, mas sabe-se que a anfetamina provoca mudanças nos neurônios e nas enzimas do fígado. Uma pequena dose inicial provoca a ativação de certo número de neurônios mas, o seu uso continuado, inibe essa ativação provocando a necessidade do aumento da dosagem usada.

A verdade é que nem sempre o vício está associado à tolerância. Mas há certeza de que o vício é provocado pela dependência do organismo, ou seja, há o vício quando o organismo para funcionar, exige o uso continuado da droga.

Segundo Arthur Guerra de Andrade a: ${ }^{12}$

OMS estabeleceu alguns critérios para o diagnóstico de dependência, que são: 1) um forte desejo ou senso de compulsão para consumir a substância; 2) dificuldade de controlar o comportamento de consumir a substância em termos de seu início, término ou níveis de consumo; 3) um estado de abstinência fisiológico quando o uso da substância cessou ou foi reduzido, evidenciado pela vivência de sintomas físicos ou psicológicos desagradáveis ou uso da mesma substância (ou de uma intimamente relacionada) com a intenção de aliviar os sintomas da abstinência; 4) evidência de tolerância de tal forma que doses crescentes de substâncias são requeridas para alcançar os efeitos originariamente produzidos por doses mais baixas; 5) abandono progressivo dos prazeres e interesses alternativos em favor do uso da substância, aumento na quantidade se necessário para obter ou usar a substância ou para se recuperar de seus efeitos; e, 6) persistência do uso a despeito de evidências claras de conseqüências nocivas devido ao uso das substâncias.

A síndrome de abstinência surge quando o viciado suspende o uso da droga e passa a sofrer distúrbios físicos e comportamentais, sintomas esses que desaparecem completamente assim que o viciado usa novamente a droga. Em geral podemos citar tremores, tonturas, ansiedade, insônia, perda do apetite, delírios, sudorese, convulsões e psicose.

Os sintomas de abstinência da anfetamina variam de pessoa para pessoa, indo desde uma forma amena até uma necessidade incontrolável da droga.

$\mathrm{O}$ viciado ameno em anfetamina, experimenta um entusiasmo ou baixa capacidade de avaliação e pode facilmente esconder o seu vício dos que o rodeiam, atribuindo as falhas do seu comportamento ao excesso de trabalho ou a uma irritação temporária.

12 Drogas. Disponível em: <www.clinicaarthurgerra.com.br>. Acesso em: jun. 2012 
O dependente mais grave não consegue esconder o vício, pois as suas atitudes fogem do seu controle. Evidencia doenças mentais como a psicose, às vezes tenta suicídio, tem comportamento que o compromete socialmente.

Depois de atingir o grau máximo de dependência, dificilmente o viciado em anfetamina se recupera totalmente mesmo com tratamentos modernos.

Ao suspender o uso da anfetamina é comum:

A sonolência prolongada, podendo dormir dias, semanas ininterruptamente, como resposta ao longo período de estímulo provocado pelo uso contínuo da droga. Por isso não é bom despertá-lo.

Numa fase seguinte, o abstêmio entra numa fase de forte depressão. Nesse período seu comportamento é bastante instável, variando entre irritação, apatia, ansiedade, medos excessivos e obsessões. Em geral podemos citar o que se observou num viciado em anfetamina numa crise de abstinência: crise depressiva profunda e duradoura acompanhada de fadiga crônica; letargia; hiperfadiga; apatia; ansiedade e distúrbios do sono além de ideias suicidas que podem persistir durante meses. Sintomas mais pronunciados foram observados em usuários de metanfetaminas como ice e crystal.

\section{- Psicose provocada por anfetamina}

Um usuário crônico de anfetamina acaba desenvolvendo sinais físicos, comportamentais e mentais da toxidade ou efeitos perigosos da droga. A mais extrema manifestação de intoxicação por anfetamina é um estado paranóide chamado de "psicose anfetamínica". E, durante essa fase o indivíduo passa a suspeitar de todos e imagina que as pessoas estão preparando armadilhas para pegá-lo.

Seu estado de saúde e de higiene pessoal se deterioram, e se o uso for intravenoso exibirá as marcas de injeções com infecções e abscessos.

O comportamento geral é de nervosismo, irritabilidade e inquietação devido à constante estimulação provocada pela droga. Aparenta confusão mental. Qualquer momento pode tornar-se violento e agredir fisicamente a si ou quem estiver próximo; se continuar a tomar a droga pode ter crises de alucinações (percepção sem objeto, em que a pessoa vê, ouve ou sente algo que não existe e o delírio pode ser definido como um falso juízo da realidade, em que o indivíduo passa a atribuir significados anormais aos eventos que ocorrem a sua volta) ${ }^{13}$ e será com muita facilidade confundido com esquizofrênico paranóide.

13 ANDRADE, Arthur Guerra de. Droga: atualização em prevenção e tratamento. Curso de treinamento em Drogas para países africanos de Língua Portuguesa. Disponível em: <www.clinicaarthurguerra.com.br>. Acesso em: jul. 2012. 
$\mathrm{O}$ indivíduo intoxicado por anfetamina não se convence que a droga é responsável por suas percepções, estado de alerta constante, curiosidade e medos incontroláveis.

As pessoas que passam pela psicose anfetamínica revelam alucinações visuais e auditivas que não se confundem com as provocadas pelo L.S.D. e nem pela esquizofrenia. A característica encontrada mais frequente na psicose anfetamínica é a ocorrência de alucinações táteis; a pessoa acredita possuir vermes ou insetos em seu corpo. Nos casos mais graves o usuário diz que sente os cristais de anfetamina sob a pele. Está sempre se coçando, se arranhando, se fere, chega a usar facas e navalhas para permitir a saída dos bichos do corpo.

Chega a ser relativamente comum a confusão entre esquizofrenia paranóide e psicose anfetamínica e, essa confusão teve início nos anos 50, quando as pessoas eram hospitalizadas e tratadas de esquizofrenia por mais de três anos, até com eletrochoques, mas continuavam ingerindo anfetaminas, agravando, dessa forma, a psicose.

- Anfetamina e comportamento violento

Os primeiros casos de violência relacionada com o uso de anfetamina começaram a surgir em fins de 50, quando essa droga se alastrou, por via intravenosa, na Califórnia, EUA.

Em 1963 as fontes legais da droga passaram a ser controladas pelas autoridades surgindo o "mercado negro" abastecido por laboratórios de "fundo de quintal". Como altas doses eram injetadas nas veias o efeito que acabou surgindo foi o delírio de perseguição, e, como muitos andavam armados, o aumento da violência foi inevitável.

Os viciados se envolviam em crimes para a obtenção da droga e, como as mesmas eram misturadas com inúmeras outras substâncias, na medida em que os usuários descobriam essas misturas, ficavam mais violentos. Percebeu-se, assim, que a anfetamina potencializa a tendência à violência. Esse comportamento violento, acelerado e impaciente é notado até hoje no usuário de anfetamina, mesmo não sendo injetada, daí ser contra-indicada a guarda de filhos aos pais viciados em anfetamina.

- Ecstasy ou pílula do amor

Em 1912, o laboratório alemão Merck isolou, acidentalmente, o MDMA e em 1914 o patenteou, como inibidor do apetite, o qual não chegou a ser comercializado.

Em 1960, foi redescoberto e, sabendo-se que essa era uma droga psicoativa, inúmeros terapeutas passaram a utilizá-la, chegando afirmar que ela era a "penicilina da alma". 
De 1977 a 1985 na psicoterapia seu uso foi maravilhoso, pois uma sessão de 05 horas com a droga equivalia 05 meses de terapia.

Em 1984 começou a explosão do ecstasy, nome dado ao MDMA pelos vendedores, por uma questão de marketing. Até então a droga era vendida legalmente e usada por estudantes americanos. As casas noturnas acabaram substituindo a cocaína por ela; mas, seu uso desenfreado levou as autoridades americanas a considerá-la ilegal, uma vez que representava muito perigo à população.

Apesar do combate pelos órgãos mundiais contra o consumo de ecstasy, alguns anos depois, das medidas da DEA e OMS, surge em Ibiza, uma ilha da Espanha, o cenário musical e cultural de onde provém o estilo "dance".

O estilo "dance" é um movimento cultural caracterizado pelo pacifismo, pela busca incessante da diversidade e pelo caráter hedonista da dança ao som da música eletrônica. $^{14}$

Em 1987, em Ibiza, na Espanha, ao som da música eletrônica, reuniram-se milhares de jovens, sob o efeito do ecstasy, LSD e haxixe. Esses jovens eram levados ao delírio e num imenso palco de madeira, começavam a praticar "striptease", terminando em sexo explícito, sob o aplauso enlouquecido da multidão. Ao final daquele verão, foi espalhado pelo mundo, esse tipo de movimento, tendo como desdobramento a "cultura dance", nascendo as festas raves, que tomou grande força na Inglaterra e cruzou o Atlântico, voltando para os EUA. Hoje os comprimidos de ecstasy são trazidos por "Djs", "promoters" de baladas que vêm de fora do Brasil. Pagam menos de 5 dólares o comprimido e vendem aqui por 50 a 60 reais. (CARLINI, Elisaldo Araújo; et al. O uso do êxtase (MDMA) na cidade de São Paulo e imediações: um estudo etnográfico. Jornal Brasileiro de Psiquiatria. v. 51, n. 2, 2002.)

O ecstasy é também conhecido como a "droga social”, pois, normalmente é utilizada por grupos e não por indivíduos isoladamente. Os comprimidos de ecstasy podem conter apenas MDMA ou anfetamina, cafeína e metanfetamina (ice). Normalmente seu princípio ativo é o mesmo do LSD. O MDMA possui propriedades alucinógenas e estimulantes, seguido de desinibição. A apresentação é em comprimidos coloridos de formas variadas e identificados por logotipos. Quanto a seus efeitos na fisiologia humana é a diminuição da reabsorção da serotonina, noradrenalina e dopamina no cérebro onde, estas substâncias, ficarão em maior contato entre as sinapses, causando euforia, bemestar e alteração na percepção sensorial. Provoca instabilidade de humor, pensamento desordenado e suicida, alterações visuais, auditivas ou de percepção somatossensória.

14 COLLIN, M. E.; GODFREY, J. Altered state: the story of ecstasy culture and acid house. London: Serpent's Tail, 1998. 
Devido a grande estimulação psicomotora que provoca o humor do usuário, oscila de uma euforia para uma ansiedade intensa acabando num temor.

A intoxicação pelo ecstasy pode causar sérios danos à saúde do usuário, tornando evidente uma doença psiquiátrica que existia em estado latente. Seu efeito maléfico reflete-se especialmente no fígado, no coração e no cérebro, comprovado por autópsia, feita na Universidade de Sheffield, na Inglaterra, em sete pessoas, entre 20 e 25 anos, mortas pela ação do ecstasy. Em todas as amostras analisadas, foram observadas grandes extensões de tecido necrosado e sinais de icterícia na pele e nas mucosas. ${ }^{15}$ Em altas doses produz hipertermia, a temperatura do corpo chega até 42 graus centígrados, daí o drogado beber muita água até em excesso (descreveu-se o caso de um indivíduo que morreu após a ingestão de 13 litros de água, revertendo o quadro para hipotermia e até edema cerebral); falência hepática; graves riscos cardiovasculares (daí o grande número de AVC e infartos dentre os jovens). Produz ainda a neurodegeneração, perda de peso (favorecido pela dança exaustiva). Causa também agitação, crises de pânico, dores musculares e taquicardia. Como provoca no usuário forte sentimento de empatia e conforto, como diz Eduardo Del-Campo é usado cada vez mais em festas da alta sociedade, festas raves e discotecas. ${ }^{16}$ Normalmente são utilizados nas baladas de finais de semana e como se divertem à exaustão, acaba ocorrendo a depressão no meio da semana, causada pelo esgotamento da produção de serotonina. Essa depressão pode ser grande e prolongada, levando ao suicídio. O uso contínuo pode acarretar a diminuição dos níveis de serotonina, com queda da libido, crises de pânico, e depressão crônica.

Uma observação importante a ser feita, consiste na vulnerabilidade que envolve os usuários da pílula do amor, pois eles têm uma sensação de auto- confiança e aumento da impulsividade, e acabam mantendo relações sexuais sem maiores cuidados, o que leva a contrair doenças sexualmente transmissíveis, e a AIDS. ${ }^{17}$ Além disso, após a saída das baladas, ainda sob o efeito das substâncias utilizadas, saem dirigindo colocando em perigo suas vidas e as vidas de inocentes.

As mulheres tornam-se desinibidas, perdem o pudor e demonstram acentuado desejo para o sexo, de preferência em grupo e com diferentes parceiros. Em altas doses, podem acarretar o "flash", um leve orgasmo em todo organismo, parecido com o causado pela heroína. Em realidade não estão fazendo sexo, mas, sob a ação da droga, em frenética agitação, despidos e abraçados, rolam uns sobre os outros até a extenuação. Com o tempo a verdade, é que o ecstasy acaba produzindo no homem a impotência e na

\footnotetext{
15 Journal of Clinical Pathology, Inglaterra, jan. 1996.

16 DELL-CAMPO, Eduardo Roberto Alcântara. Medicina legal II. São Paulo: Saraiva, 2009. (Coleção Curso \& Concurso; coordenação Edílson Mougenot Bonfim).

17 CARLINI, Elisaldo Araújo et. al. op. cit.
} 
mulher a frigidez e apatia sexual. Daí o aumento assustador do uso de um ingrediente extra: o Viagra, o mais popular medicamento para disfunção erétil. ${ }^{18}$

Os sintomas do ecstasy, puro ou misturado, lembram os da psicose. Muitos viciados têm sido classificados, erroneamente, como doentes mentais esquizofrênicos ou paranóicos. $^{19}$

Segundo o CEBRID $^{20}$ os efeitos relatados pelo uso do ecstasy são: hipersensibilidade ao toque, especialmente nas áreas erógenas; aumento do desejo sexual; pupilas dilatadas; sensibilidade ocular; sensação de aumento de energia; eliminação da ansiedade; relaxamento profundo; pensamentos positivos; simpatia por estranhos; supressão da necessidade de comer, beber e dormir por até três dias; tremores; ranger involuntário dos dentes; problemas musculares; visão embaçada; alucinações; náuseas e calafrios; transpiração e aumento da temperatura corpórea.

Stella Pereira de Almeida, em sua dissertação de mestrado, ${ }^{21}$ estudou o perfil psicológico e social dos usuários de ecstasy na cidade de São Paulo, e o resultado de sua pesquisa apontou: são integrantes da classe média; jovens; herossexuais; solteiros; nível superior; portadores de tatuagens e "piercings"; frequentadores de festas "raves"; admiradores de músicas eletrônicas; usuários de outras drogas; uso em companhia de outros jovens, principalmente nos fins de semana e nas férias; adquirem as drogas no local das festas "rave" e em locais de lazer noturno, geralmente de amigos e conhecidos.

Visando maior efeito o ecstasy está sendo misturado com morfina e cocaína, ou mesmo com heroína e cocaína ou mais recentemente com heroína e LSD. Muitas vezes o traficante vende simples adrenalina ou MDMA como se fosse ecstasy. A duração de seu efeito, em média, é de oito horas, mas isso pode variar de pessoa para pessoa, porque as enzimas que eliminam a droga não estão presentes nas mesmas quantidades em todas as pessoas. Aqueles que possuem maior quantidade de enzima metabolizadora eliminam mais rapidamente. A previsão do tempo de duração da atividade não é precisa por causa dos metabólitos ativos, ou seja, mesmo o ecstasy tendo sido metabolizado, os produtos dessa metabolização continuam exercendo atividade psicoativa como se fosse o próprio ecstasy. Assim um efeito não necessariamente agradável, pode se prolongar por mais de oito horas. Quaisquer das misturas citadas representam um coquetel explosivo, comprovando não ter limite a busca desse mundo maravilhoso, que só existe na imaginação dos doentes, dos fracos, dos desinformados, dos inseguros, dos débeis e dos imbecis.

\footnotetext{
18 FOLHA S.PAULO, São Paulo, 20 jun. 2004. p. C6.

19 Cid Martins Batista.Professor Titular da Universidade Federal de Viçosa, MG. Ex-Professor Visitante da Universidade do Arizona, USA.

20 CEBRID: Centro Brasileiro de Informações sobre Drogas Psicotrópicas. Boletim CEBRID, n. 43, dez. 2000; jan./fev. 2001.

21 Id. Ibid.
} 


\section{- Metanfetaminas}

A metanfetamina foi sintetizada em laboratório em 1887. Esse estimulante sintético tem uma estrutura química semelhante a efedrina (estimulante natural) encontrado em plantas do gênero ephedra.

Em 1930 foi comercializada nos EUA como descongestionante nasal, passando depois a ser prescrita para casos de depressão, mal de Parkinson, epilepsia, hiperatividade infantil, obesidade, narcolepsia (distúrbio caracterizado pelo excesso de sono), impotência, apatia dos idosos etc. Dentre todas as indicações todavia, as ações de diminuir o apetite, o sono e aumentar as performances física e intelectual se destacaram, e por isso, foi largamente utilizada ganhando o nome de "speed". No Brasil seu uso foi registrado nas décadas de 50 e 60 através do medicamento pervitin, consumido por jovens universitários e por caminhoneiros.

Apesar de proibida em 1970, continuou a ser produzida clandestinamente em baixa escala, em alguns estados dos EUA. Mais tarde, o tráfico organizado mexicano voltou a produzir o "meth", como era chamada a metanfetamina, em larga escala, distribuindo para todo território americano numa forma mais poderosa e, atualmente, mais da metade de toda produção mexicana é consumida em todo mundo.

Alguns estudiosos afirmam que o ice, como é mais conhecido hoje, (assemelha-se a pequenos cristais de gelo) é a versão turbinada de anfetamina, geralmente usada por internautas adolescentes e viciados por videogames. Tal afirmativa, no entanto, é contestada por outros, como a (INTERNATIONAL NARCOTICS CONTROL BOARD. Precursors and Chemicals frequently used in the illicit manufature of narcotic drugs and psychotropic substances. Vienna: United Nations Publications. 1998 in Profissionais da saúde- por Adalberto Tripicchio-http://www.brasilmedicina.com.br/notícias/pgnotícias).

Esses usuários passam horas com os olhos grudados na tela do computador; o corpo é uma fonte de energia, o raciocínio fica mais rápido, os reflexos motores mais aguçados. Não sentem cansaço e, a luz vinda do monitor em conjunto com a droga mais os excitam. Após a ingestão do ice o coração dispara, a pressão arterial sobe, as pupilas dilatam e o cérebro os leva a uma sensação de bem estar. Também denominada "droga virtual", proporciona uma viagem perigosa uma vez que pode levar à convulsões e à parada cardíaca. As metanfetaminas são drogas imprevisíveis e letais, possuem muitos nomes: gelo, crank, meth, vidro, speed, cristal. É como a cocaína, um potente estimulante do sistema nervoso central, é uma das drogas que mais cresce em uso. É um fármaco mais potente que a d-anfetamina e é facilmente sintetizada em laboratórios clandestinos através de reagentes químicos facilmente obtidos.

O cloridrato de metanfetamina é usado por via oral, por injeção, intravenosa e por via intranasal. Sua aparência varia dependendo de como é usada. É branca, sem 
cheiro, de gosto amargo e dissolve facilmente na água. Outra forma dessa droga é "cristal" ou "gelo" ou ice assim denominada por sua aparência, é fumada como o crack e seu efeito eufórico é mais durável.

A metanfetamina tem grande potencial de dependência e seu uso crônico pode levar ao aparecimento de comportamentos psicóticos devido ao dano que causa no SNC. Seu consumo explodiu com muita rapidez; há bem pouco tempo era mal conhecida pelas autoridades, desta forma, para melhor observar as reações dos usuários, equipes de investigadores se infiltravam nos pontos mais prováveis de sua circulação, as lojas de videogame e salões de fliperama. ${ }^{22}$

O ice é uma espécie de crack sintético podendo ser tão devastador quanto ele alerta o psiquiatra Ronaldo Laranjeira da Universidade Federal de São Paulo. Produzido na China, na Tailândia e nas Filipinas chegou à Europa ocidental depois de atravessar a Rússia. No Brasil entrava via Paraguai, era muito barato e por isso as autoridades temiam que essa droga logo se alastrasse além dos internautas de classe média e ganhasse as ruas. $^{23}$

\section{- Efeitos}

$\mathrm{O}$ uso crônico e contínuo, causa nervosismo, irritação e paranoia. $\mathrm{Na}$ realidade uma psicose similar à esquizofrenia com alucinações visuais e auditivas. $\mathrm{O}$ comportamento é violento e irregular; altas doses produzem severa depressão, insônia por muitos dias e, nesse período de "fissura", o usuário em busca de relaxamento procura por doses maiores, o que só aumenta a paranoia, a insônia, nervosismo e sensação de perseguição, com julgamento de "trama contra si". Isso tudo gera frustração, causando no indivíduo um comportamento imprevisível e violento.

A metanfetamina aumenta os batimentos cardíacos, a temperatura do corpo, pressão sanguínea e o ritmo da respiração. Dilata a pupila e produz hiperatividade temporária, euforia, sensação de aumento de energia e tremores. Além disso, causa excitação e grande sensação de prazer, o que leva à despreocupação do uso de preservativos nas relações sexuais. Segundo os estudiosos atinge $1500 \%$ o valor normal de liberação de dopamina no cérebro, provocando uma sensação de prazer insaciável, só para comparar, a cocaína atinge o nível de $400 \%$.

\footnotetext{
22 (VEJA - p. 096- 04 -10-2000).

23 (Cid Martins Batista -Professor Titular da Universidade Federal de Viçosa, MG, Ex-Professor Visitante da Universidade do Arizona, USA).
} 


\section{- Cápsula do Vento}

Tem o nome de "cápsula do vento" por ser composta de pequenas quantidades de um pó branco acondicionado em cápsulas transparentes.

Esse tipo de droga se tornou um grande problema na Europa, considerando a grande facilidade de fabricação em fundo de quintal, com muitas impurezas e o uso de substâncias altamente tóxicas e perigosas. O resultado foi o aumento de mortes. O desespero foi tamanho que, em lugares de concentração de jovens as autoridades levavam equipamentos para que as drogas fossem examinadas e os resultados divulgados para o consumidor, sendo o mesmo avisado das impurezas, inclusive se letais (Instituto Brasileiro Giovanni Falcone).

A DOB, como também é chamada, segundo as reações dos usuários pode se tratar de um derivado de anfetamina, ou cristais de LSD. Quando derivada de anfetamina e colocada na cápsula transparente, dando a impressão que a mesma está vazia, possui, na realidade, cerca de 1 a 1,5 mg de anfetamina, sendo adicionado um átomo de bromo, elemento químico que potencializa o efeito da droga, aumentando o tempo de ação, pondo em risco a vida do usuário. Segundo o Instituto Nacional de Criminalística da Polícia Federal, a primeira apreensão dessa droga foi em novembro de 2004 no litoral de Santa Catarina, e, para ela, essa droga é comparada ao ecstasy. E, sendo desta forma, acreditam que há espaço para a DOB no Brasil assim também pensando, o psiquiatra Arthur Guerra de Andrade, presidente do Conselho Técnico e Administrativo do GREA do Departamento de Psiquiatria da USP. A partir da apreensão desta droga em São Paulo, na posse de universitários, percebeu-se que o perfil dos traficantes de drogas sintéticas está se modificando. Pouco se sabe sobre ela, assemelha-se ao LSD, é uma droga sintética alucinógena cujo efeito, segundo consta, pode durar até 30 horas. É tomada por via oral, podendo causar pânico, paranoia e alucinações, por isso é denominada como a "droga do medo". Todavia essas sensações dependem do estado de humor do usuário e da quantidade tomada. É estimulante e alucinógena. Tomada em altas doses, causa perda de memória, violência desmedida e irracional. Como o início de seu efeito não é tão imediato, no começo, os usuários desconfiados de sua ação, pois não viam o interior da cápsula, tomavam mais de uma, o que os levava a permanecer dias sob o efeito da droga apresentando graves quadros de paranoia e alucinações. ${ }^{24}$

24 Disponível em: <www.saudeemmovimento.com.br/reportagem/noticia_exibe.asp?>. 


\section{- Conclusão}

O estudo realizado demonstrou um crescimento acelerado da produção e uma explosão assustadora do consumo de anfetamina e derivados, especialmente nos últimos anos com a popularização das festas "raves". Apenas nas últimas décadas as apreensões aumentaram, subindo de 40 toneladas de 2000/2001 para quase 90 toneladas em 2010/2011. A primeira pesquisa global sobre ecstasy e anfetaminas, realizada pelo Escritório das Nações Unidas contra Drogas e Crime (UNODC. http://www.unodc.org.br) revela que a produção dessas drogas é estimada em mais de 500 toneladas por ano, sendo que cerca de 40 milhões de pessoas fizeram uso nos últimos 12 meses. O que representa cerca de $1 \%$ da população mundial. A sua fabricação é muito fácil, sendo possível produzilas em pequenos laboratórios e, de acordo com o gosto e público alvo.

Outrossim, percebeu-se que essas drogas são consumidas, principalmente, por jovens entre 14 a 30 anos (mudando rapidamente essas idades, para menos de 14 anos e mais de 30 anos), com grau de instrução superior, ou correspondente a sua idade, pertencentes a classe média, média alta e alta.

Como provocam falta de apetite, são muito procuradas por mulheres que buscam emagrecimento rápido. Desde 1998, o uso de anfetamina, cresceu 500\% em nosso país. ${ }^{25}$ A pesquisa com essas mulheres, demonstrou que a anfetamina provoca reações secundárias como, irritações incontroláveis, agitação descomunal, insônia e depressão, levando, em alguns casos isolados, ao suicídio, tendo sido registrado, até mesmo, violências contra os próprios filhos, apesar de amá-los. ${ }^{26}$

O Ambulim (Ambulatório de Bulemia e Transtornos Alimentares do Instituto de Psiquiatria do Hospital das Clínicas) é considerado o maior centro especializado do Brasil e da América Latina, oferecendo tratamento gratuito para pacientes de qualquer lugar do país. Uma vez que os transtornos alimentares são problemas multifatoriais (genéticos, biológicos, sócio culturais, familiares e psicológicos), o tratamento oferecido é realizado com apoio de equipe multidisciplinar, formada por médicos psiquiatras, nutricionistas, psicólogos, terapeutas familiares e educadores físicos. O Ambulim oferece diversos cursos nas áreas de saúde mental, em longo e curto prazo.

Os transtornos alimentares são caracterizados por perturbações no comportamento alimentar, que levam ao emagrecimento extremo, à obesidade, ou outros problemas físicos, como anorexia nervosa e a bulemia. Os problemas decorrentes dos transtornos alimentares têm como característica um medo excessivo de engordar, uma percepção distorcida da forma corporal. Há quadros menos graves, mas mesmo assim, 
são marcados por uma insatisfação com o corpo, o que os leva a busca incessante por dietas e recursos extremos para emagrecer e uma das formas, além de outras é o uso das anfetaminas.

O consumo pelos caminhoneiros, que necessitam permanecer acordados nas longas viagens, nos explica os terríveis acidentes nas estradas, sem nos esquecer também, a constatação da progressão do tipo de droga, qual seja, o uso da cocaína.

No mundo dos esportes, além de prejudicar o desempenho natural do atleta, acarreta o "doping", que é duramente reprimido por todas as autoridades organizadoras de eventos esportivos, especialmente pelo Comitê Olímpico Internacional.

O estudo do uso indevido de anfetamina e derivados, demonstra que a tática de assustar o usuário é ineficaz. Apesar de necessário, um programa nacional de desestímulo ao uso de drogas não é suficiente. A situação de cada comunidade deve ser estudada, com o auxílio de pais, professores e autoridades locais, que necessitam receber orientações sobre esse problema crucial que está batendo à porta de todos nós. As informações às crianças e adolescentes devem começar mais cedo, porque o assédio começa a ocorrer cada vez mais cedo também. O melhor caminho é a prevenção, a informação, a educação e principalmente a religiosidade.

O consumo de drogas é uma doença social, cujo vírus é a própria droga, o transmissor é o traficante e o hospedeiro é o usuário. É um problema de saúde pública. É bem verdade que a Anvisa determinou terminantemente a proibição da venda de remédios a base de anfetaminas, (anfepramona, femproporex e mazindol) para a redução do apetite para a perda de peso rapidamente, mas e a repressão ao uso ilícito dessa droga que infelizmente ainda continua? O ice, por exemplo, é uma droga potente que lesa o sistema imunológico, possibilitando ao usuário doenças dos mais variados tipos. Já a “cápsula do vento", ou "cápsula do medo" demonstra, pelos seus efeitos, uma tendência de consumo de alucinógenos que tem cada vez mais se tornado popular desde 90. Por outro lado, a procura constante, por reações novas, leva os jovens a misturar cada vez mais os tipos de drogas, ou mesmo fazendo uso de medicamentos tarja preta como estimulantes, colocando em sério perigo suas vidas. ${ }^{27}$

O ecstasy, por sua vez tornou-se frequente em quase todos os tipos de festas e comemorações. Quando ingerido com bebidas alcoólicas, pode causar choque cardio-respiratório levando a morte, ou mesmo isoladamente, se prolongadamente leva à degeneração celular no cérebro.

27 JORNAL FOLHA S.PAULO -20-06-2004- p. C1 e C6; JORNAL FOLHA DE S.PAULO - 28-09-2010- p. C 11- JORNAL O ESTADO DE SÃO PAULO - 05-11-2006 - p. A27). 
O consumo de drogas gera gastos incalculáveis na área da saúde, reduz a produtividade dos usuários, destrói famílias em geral, leva ao aumento da violência e criminalidade. $\mathrm{O}$ indivíduo para sustentar o vício dificilmente não se torna traficante.

Muito dinheiro, que poderia ser melhor empregado na área da saúde em geral, é gasto para fortalecer a polícia, o patrulhamento nas regiões de fronteira, os sistemas judiciais e os programas de tratamento e reabilitação. Os custos sociais também são elevados para combater a violência nas ruas, aumento da criminalidade, os conflitos de gangues o medo e a decadência urbana.

A dependência psicológica nos casos de anfetamina e drogas derivadas é extraordinária; a tolerância declarada leva à necessidade de maiores quantidades, não só por essa razão, mas também pela abstinência. Ainda que um indivíduo viciado nesse tipo de drogas, fique por um período longo sem consumir, na medida em que ingira um comprimido, o vício pode voltar com a mesma intensidade.

Após o vício, a recuperação é difícil, dolorosa; requer muitos cuidados, tratamentos e colaboração familiar. Como o viciado viveu para a droga necessitará reorganizar a sua vida, sua família, seu trabalho e autoestima. Na Universidade Presbiteriana Mackenzie, por exemplo, há o Sopedi, dirigido a não-viciados, é claro, um Serviço de Orientação Psicopedagógica (hoje com uma função muito mais extensa), para jovens alunos de Direito)

As drogas sintéticas dos tipos anfetamina e drogas derivadas, são misturas psicoativas desenvolvidas em laboratório, e, um dos seus maiores consumidores são os jovens, seja para descansar de seus problemas, ou passar a noite toda dançando em baladas ou para emagrecer mais rapidamente. Enfim, simplesmente pelo prazer que elas podem proporcionar. São jovens do meio social de maior poder aquisitivo, pois essas drogas são caras, adquiridas de maneira "lícita", o que dificulta seu controle.

O perfil dos usuários e do traficante dessas drogas sintéticas, nos indica que são pessoas, em princípio, bem aquinhoadas economicamente, e que poderiam trilhar caminhos de sucesso com futuros brilhantes, não se justificando assim, essa busca desmesurada de prazer, que acaba levando para a destruição do potencial e preparo, que sua condição social permitiu. Normalmente querem roupas caras, frequentar lugares luxuosos, carros da moda e, além de se sentirem sufocados pelas tensões do momento em que vivemos, são atropelados na corrida pelo sucesso.

Querem tudo, podem tudo e o que estão conseguindo é a morte precoce em acidentes, confrontos com a polícia, contaminações pelas DST e pelo HIV. As estatísticas têm mostrado aumento dessas doenças entre os jovens, alem de comprovar que, de 1980 a 
2010, houve um aumento de $376 \%$ de morte de jovens entre 14 a 19 anos principalmente, sem exclusão das idades até 30 anos. $^{28}$

Realmente problemas existem, quem não os tem? Todavia a droga cobra muito caro, pelos prazeres que proporciona, e não é "derretendo" os neurônios, adquirindo doenças e jogando fora futuros promissores que mudarão o que há de ruim que aí está.

Os jovens devem aprender valores morais, éticos, a cidadania, convivência, o respeito à vida, própria e a de seus semelhantes, e, acreditar em algo muito forte e acima dos valores apenas materiais, isto é terrenos, e, esses valores devem ser ensinados pelos pais, desde a tenra idade, para que os frutos possam surgir mais tarde, na pré-adolescência, juventude e idade adulta.

Querer ensinar esses valores, mais tarde, será, evidentemente, um trabalho muito árduo. ${ }^{29}$

A questão das drogas movimenta grandes polêmicas no mundo todo, isto porque esse problema não é privativo do Brasil. A verdade é que deve mesmo haver muita discussão, pois o que está em sério risco e está se perdendo é o valor maior do mundo e do planeta, a esperança do dia de amanhã, as crianças e os jovens.

São Paulo, setembro de 2013.

\section{Referências}

ALMEIDA JÚNIOR, A.; COSTA JÚNIOR, JB de O. Lições de medicina legal. 20. ed. São Paulo: Companhia Editora Nacional, 1987.

ABANNE (São Luis, 1 a 4 de julho de 2003).

ABREU, Carolina de Camargo. Festas raves: o teatro do ritual. In: VIII Encontro de Antropólogos do Norte e Nordeste.

AGÊNCIA NACIONAL DE VIGILÂNCIA SANITÁRIA (ANVISA). Parecer técnico-cientifico do Grupo Assessor de Estudos sobre Medicamentos Anorexígenos.

ALMEIDA, Stella Pereira de. Sintéticas. Recreativas e ilegais: Drogas de uma geração química. In: SILVEIRA, Dartiu Xavier da; MOREIRA, Fernanda Gonçalves (Org.). Panorama atual de drogas e dependências. São Paulo/Rio de Janeiro/Rib. Preto/Belo Horizonte: Atheneu, 2006.

AMBULIM: Ambulatório de Bulemia e Transtornos Alimentares do Instituto de Psiquiatria do Hospital das Clínicas.

\footnotetext{
28 (Jornal Agora - Dia 18-07-2012. p. A7. Jornal Folha de São Paulo - Dia 18-07-2012. p. C5. Jornal O Estado de São Paulo - Dia 18-07-2012. p. C5).

29 MUAKAD, Irene B. A cocaína e as suas formas de consumo. APMP Revista, p. 66-81, maio/ago. 2009.
} 
ANFETAMINAS. Disponível em: $<$ http://www.unifesp.br/dpsicobio/cebrid/folhetosanfetaminas_. htm>. Acesso em: jun. 2011.

ANDRADE, Arthur Guerra de. Drogas. Atualização em prevenção e tratamento - Curso de Treinamento em drogas para países africanos de língua portuguesa. Disponível em: <www. clinicaarthurguerra.com.br>. Acesso em: jun. 2012.

ANDRADE, Arthur Guerra; NICASTRI Sérgio; TONGUE, Eva. Drogas: Atualização em prevenção e tratamento. Editado sob o patrocínio de PNUCD (Programa das Nações Unidas para o Controle Internacional de Drogas) s.d.

BATISTA, Cid Martins. Matéria publicada deste Professor Titular da Universidade Federal de Viçosa, MG. Ex-Professor Visitante da Universidade do Arizona, USA in e-mail: chatista@mail. ufv.br

BUCHER, Richard. Drogas, o que é preciso saber para prevenir. 3. ed. São Paulo: Fundo de Solidariedade do Estado de São Paulo, 2003.

CALIL, Marines A. Aventura do estilo: um pequeno estudo dos fashion clubs do gênero dance music na cidade de São Paulo. 1994. Dissertação (Mestrado) - PPGAS, Universidade de São Paulo, São Paulo.

CALIL, Marines A. O retrato do Nations Disco Club: Os neodândis no final dos anos 80. In: $\mathrm{Na}$ Metrópole: Textos de Antropologia urbana: EDUSP/FAPESP. 2000.

CAMINHO SEM VOLTA. Livreto educativo. DENARC. São Paulo. s.d. 2009.

CANTWELL, B. McBridge Aj. Self detoxification by anphetamine dependent patients: a pilot study. Drug Alcohol Depend, n. 49, p. 157-63, 1998.

CARLINI, Elisaldo de Araújo; NAPPO, Solange; NOTO, Ana Regina; BAPTISTA, Murilo Campos. O uso do Êxtase (MDMA) na cidade de São Paulo e imediações: um estudo etnográfico. Jornal Brasileiro de Psiquiatria, v. 51, n. 2, 2002.

CARVALHO, Hilário Veiga de. et al. Compêndio de medicina legal. São Paulo. Saraiva, 1987.

CAVALIERI, Ana Lúcia Ferreira, EGYPTO, Antonio Carlos. Drogas e prevenção: a cena da reflexão. 4. ed. Saraiva. São Paulo, 2004.

CEBRID - CENTRO BRASILEIRO DE INFORMAÇÕES SOBRE DROGAS PSICOTRÓPICAS - Funciona no Departamento de Psicologia da UNIFESP. É uma entidade sem fins lucrativos. É constituído por uma equipe técnica composta por especialistas nas áreas de medicina, sociologia, farmácia-bioquímica, psicologia e biologia. Boletim CEBRID, n. 43, dez. 2000; jan./fev. 2001.

CEBRID - Secretaria Nacional Antidrogas. Gabinete de Segurança Institucional. Jogo de folhetos explicativos sobre drogas psicotrópicas. São Paulo, CEBRID/EPM. s.d. 
CEBRID - Centro Brasileiro de Informações sobre Drogas Psicotrópicas. Secretaria Nacional Antidrogas. Gabinete de Segurança Institucional. Livreto Informativo sobre drogas psicotrópicas. São Paulo.

CREMESP/AMB. Usuário de substâncias psicotrópicas. Abordagem, diagnóstico e tratamento. 2. ed. São Paulo, 2003.

COLLIN, M. E.; GODFREY, J. Altered State: the story os ecstasy culture and acid house. London: Serpent's Tail, 1998.

CORAZZA, Alberto. Manual de palestras. Drogas- Morte total e irrestrita. Divisão de Prevenção e Educação do DENARC.

CORRÊA, Maria Terezinha. As festas e suas fronteiras. Revista Criação UNIR, n. 26, dez. 2001.

COTRIM, Beatriz Carlini; STASEVSKAS, YANINA. Drogas: mitos \& verdades. 9. ed. São Paulo: Ática, 2000.

CROCE, Delton; DELTON JR, Croce. Manual de medicina legal. 8. ed. São Paulo: Saraiva, 2012.

D'ANDREA, Anthony A. Fischer. Global nomads: techno and new age as transnational countercultures in Ibiza in Goa. In: GRAHAM ST., John (ed.). Rave culture and religion. Londres / Nova York: Routledge, 2004. p. 236-255.

DE LIMA MS, BERIA JU, TOMASI E, MARI JJ. Use of amphetamine like appetite suppressants: a cross-senctional survey in Southern Brazil. Subs Use Misuse, v. 33, n. 8, p. 1.711-9, 1998.

DELL-CAMPO, Eduardo Roberto Alcântara. Medicina legal II. São Paulo: Saraiva. 2009. (Coleção curso \& concurso/ coordenação Edílson Mougenot Bonfim).

DIAS, J. Silva. Medicina forense. 1. ed. São Paulo: Saraiva, 2007.

ELLENHORN MJ, SCHONWALD S, ORDOG G, WASSERBERGER J. Amphetamines and designer drugs. In: ELLENHORN, MJ; SCHONWALD, S; ORDOG, G.; WASSERBERGER, J. Ellenhorn's medical toxicology: diagnosis and treatment of human poisoning. Maryland: William \& Wilkins; 1997. p. 340-55.

Ecstasy leva a perda da eficácia do cérebro. Disponível em: <http://www.cienciahoje.pt/index. php?>.

EVANGEGISTA, R.; NORITOMI, R. T. Reflexões sobre as representações dos técnicos desportivos acerca das drogas. São Paulo: Mimeo, 1993. (Pesquisa elaborada no Centro de Estudos do IMESC).

FRANÇA, Genival Veloso de. Medicina legal. 7. ed. Rio de Janeiro: Editora Guanabara Koogan S.A., 2004.

FERRARINI, Edson. Vencedor não uso drogas. Orientação sobre drogas e alcoolismo. Nossos filhos longe das drogas. São Paulo: Ed. Book Gráfica \& Editora, s.d. 
FONTANARI, Ivan Paolo de P. Sensibilidade eletrônica: música ritualidade jovem contemporânea. Poper apresentado na 24a Reunião da Associação Brasileira de Antropologia (Olinda 12 a 15 de junho de 2004). 2004.

GALDURÓZ, J.C.; NOTO, A.R.; CARLINI, E.A. IV Levantamento sobre o uso de drogas entre estudantes de $1^{\circ}$ e $2^{\circ}$ graus em 10 capitais brasileiras. São Paulo: Centro Brasileiro de informações sobre Drogas Psicotrópicas (CEBRID), 1997.

HTTP://WWW.ANTIDROGAS.COM.BR/REC TRATAMENTO.PHP

HTTP://WWW.AMBULIM.ORG.BR/

HTTP://WWW.UNODC.ORG.BR

LUKAS, Scott E. Tudo sobre drogas, anfetaminas. São Paulo: Nova Cultural, 1988.

OGA, Seizi. Fundamentos de toxicologia. São Paulo: Atheneu, 1996.

DROGA e toxidependência: O desafio de uma intervenção global (Mesma autora).

MAGNO, Luiz Carlos Freitas. Prevenção: acredite, você pode vencer. São Paulo: Empresa Jornalística RJR, 2003.

MARANHÃO, Odon Ramos. Intoxicação por maconha. Revista da Escola do Serviço Penitenciário, Porto Alegre, v. 1, n. 4, jul./set. 1990.

MARANHÃO. Odon Ramos. Curso básico de medicina legal. 8. ed. rev. e ampl. São Paulo: Malheiros, 2005.

MELO, Dirceu Antonio Leme de. Drogas: vida e morte. Vitória: Ed. Lettera, Ministério da Saúde (SITE), 1996.

MUAKAD, Irene Batista. Reflexões sobre a intoxicação canábica. Revista Ministério Público, São Paulo, p. 78-89, fev./abr. 2008.

MUAKAD, Irene Batista. A cocaína e as suas formas de consumo. Revista Ministério Público, São Paulo, p. 66-81, maio/ago. 2009.

NASCIMENTO, E. C. do; NASCIMENTO, E.; SILVA, J. P. O uso de bebidas alcoólicas e anfetaminas entre caminhoneiros. Antidrogas. São Paulo. Disponível em: $<$ http://www.antidrogas. com.br/mostraartigo.php?c=680>. Acesso em: 10 set. 2009.

PINTO, Flávio Barros (dir.). Era uma vez... o corpo humano: o fígado. Rio de Janeiro: Globo S/A. 1995.

RANG, H. P. et.al. Farmacologia. 4. ed. Tradução de Patrícia Josephine Voeux. Rio de Janeiro: Editora Guanabara Koogan S.A. 2001.

REZENDE, Joffre M. de. Linguagem médica: grod, fármaco, medicamento, remédio. Reproduzido do livro linguagem médica 3. ed. Goiânia: AB Editora e Distribuidora de Livros Ltda. 
REVISTA DROGA E FAMILIA. Órgão Oficial da Abrafam: Associação Brasileira de Apoio às Famílias de Dependentes de Drogas.

SAUNDERS, Nicholas. Ecstasy e a cultura dance. São Paulo: Publisher Brasil, 1997.

SILVEIRA, Dartiu Xavier. Um guia para a família. Brasília: Presidência da República. Gabinete de Segurança Institucional. Secretaria Nacional Antidrogas. 2002.

PALOMBA, Guido Arturo. Tratado de psiquiatria forense, civil e penal. São Paulo: Atheneu Editora, 2003.

PRIGADÃO, José Neube. Mostrar caminhos. Prevenção ao abuso de drogas e recuperação. 3. ed. São Paulo: Edições Loyola. 1999.

TIBA, Içami. Saiba mais sobre maconha e jovens. Um guia para leigos e interessados no assunto. 4. ed. São Paulo: Agora, 1998.

TONGUE, Eva. Visão geral dos problemas das drogas no mundo. p. 09.

VEJA. Ice. Chegou ao Brasil de forma tímida, mas acabou tomando conta dos jovens. p. 96 - 4 de outubro de 2000 .

Informações colhidas no Ambulim - Ambulatório de Bulemia e Transtornos Alimentares do Instituto de Psiquiatria do Hospital das Clinicas.

Maioria das informações aqui contidas foram obtidas no CEBRID.

Informações colhidas no Denarc

Informações colhidas no Centro de Recuperação "Coronel Edson Ferrarini”"

Informações colhidas no GREA - Grupo Interdisciplinar de Estudos de Álcool e Drogas 